Assessment of pulmonary function by measurement of phospholipid microviscosity in tracheal aspirates of newborns with respiratory distress syndrôme A.LABBE ${ }^{1}$, C. MOTTA ${ }^{2}$, P.ASSALI ${ }^{1}$, E.J.RAYNAUD ${ }^{1}$ 1. Service de Pédiatrie A, HOTEL-DIEU, CLERMONT-FD 2. Laboratoire de Biochimie, HOTEL-DIEU, CLERMONT-FD

Phospholipids are the major components of the pulmonary surfactant and ensure its fluidity. It is possible to evaluate their functional quality by a simple method of fluorescence polarization widely used in amniotic fluid to assess fetal lung maturity. In the present study, we have used this technique to evaluate the tensio-active properties of the phospholipids in tracheal aspirates from 150 newborns with respiratory distress.

Measurement of microviscosity was carried out using the fluorescent probe 1.6. Diphenyl 1.3.5. Hexatriene (DPH).

The microviscosity values obtained with aspirates from the neonatal control group $(n=50)$ without pulmonary pathology was always $<3$ poises.

The pathological group $(n=150)$ of newborns can be divided into two subgroups : A with favorable outcome and B with an unfavorable outcome leading to death. In group A the initial microviscosity of $5+05$ poises (mean $\pm S D$ ) decreased to $2,5 \pm 0,3$ poises a the time of extubation $(\mathrm{p}<0,001)$. In group $\mathrm{B}$ the initial microviscosity was $4,8+0,5$ poises (no significant difference $p>0,05$ ). However in this group microviscosity subsequently rose. In
all cases the ri e of microviscosity was accompagnied by deterioration in respiratory function.

We conclude that the measurement of tracheal microviscosity provides a new method for checking pulmonary function in the first days of life.

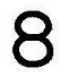

HUMAN NEUTROPHIL ELASTASE AND a -PROTEINASE IMBALANCE IN PULMONARY EFFLUENTS IN INFANTS RESCUED WITH HIGH FREQUENCY OSCILLATORY VENTILATION. Blum-Hoffmann, E., Hoffmann, G., Merritt, T.A. and Mannino, F.L. (introduced by W. Schröter). Dept. of Pediatrics, Univ.

Calif. San Diego, San Diego, Ca, USA.

Neonates failing conventional ventilation were treated with a combined High Frequency Oscillatory(HFO)-Intermittend Mandatory(IMV) system for rescue. Analysis of sequential pulmonary effluents during HFO-IMV was performed in seven of these infants. Gestational age ranged from 28-39 weeks, weight from $800-3000 \mathrm{~g}$. There was no difference between the primary pulmonary diagnoses and complicadifference between the primary pulmonary diagnoses and complica-
tions of survivors (4) and non-survivors (3). Due to the small number of collections prior to their demise, interpretation of analyses of effluents in the non-survivors is difficult. Effluents of the survivors had high concentrations of human neutrophil elastase (HNE) (range $0.013-1.712 \mathrm{ug} / \mathrm{ml}$ ) and $a_{1}$-antiproteinase $\left(a_{1}-\mathrm{AP}\right)$ (range 28.5-294.5 ug/m1), peaking at days 3 to 5 of treatment. The inverse pattern was seen for the a -proteinase inhibitor activity $\left(a_{1}-\mathrm{PI}\right)$, which decreased by $50-100 \%$ in the effluents of three of the survivors. Compared to conventionally ventilated control infants, infants with RDS or RDS/bronchopulmonary dysplasia(BPD) the HFO-IMV infants had 8.8 fold higher mean albumin concentrations and markedly lower HNE/albumin and a -PI/albumin ratios. High HNE/ albumin and reduced $\mathrm{a}_{1}-\mathrm{PI} / \mathrm{albumin}$ ratios contribute to lung injury and may facilitate the development of chronic lung disease. None of these HFO-IMV survivors had BPD. In view of the small number of cases and the high albumin levels, the significance of the low HNE/albumin and $a_{1}$-PI/albumin ratios in the effiuent of the HFOIMV infants warrants further investigation.

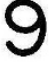

INFLUENCE OF HIGH FREQUENCY OSCILLATION VENTILATION (HFOV) AND INTERMITTENT MANDATORY VENTILATION (IMV) ON EXOGENOUS SURFACTANT DISTRIBUTION. Walther F.J. Gidding C.E.M., Van de Kamp G.M., Bevers E.M.

Depts. of Pediatrics and Biochemistry, University of Limburg, Maastricht, The Netherlands.

In premature lambs, instillation of surfactant (S) after a period of mechanical ventilation for respiratory distress sydrome (RDS) leads to a shorter duration of the clinical response than $S$ treatment at birth. The distribution of instilled $S$ probably depends on the timing of administration, but also on the type of ventilation used. The effects of IMV and HFOV on the distribution of exogenous $\mathrm{S}$ were studied in 10 premature lambs delivered at 126-132 days of gestation. All were ventilated from birth with IMV at a FiO2 of 1.0. After respiratory failure had been documented $50 \mathrm{mg}$ natural sheep $\mathrm{S} / \mathrm{kg}$ body weight, labeled with $1 \mu \mathrm{Cj}$ $\left[{ }^{14} \mathrm{C}\right]$ dipalmitoyl-phosphatidylcholine, was instilled into the trachea. Ventilation was continued for 3 hours with IMV in group $A(n=5)$ and with HFOV in group $B(n=5)$. The lambs were than sacrificed and the distribution of labeled $S$ over the lung was quantified.

Group B showed improved oxygenation and $\mathrm{CO} 2$ removal at lower mean airway pressures in comparison with group A. However, in both groups a non-homogenous distribution of labeled $S$ was documented. Central lung areas contained in general more $S$ than peripheral areas, where large differences in $S$ content were found.

We conclude that (1) surfactant instillation after the establishment of RDS leads to a non-homogenous distribution over the lung, and (2) the surfactant distribution is not influenced by the type of ventilation used.
10

HIGH FREQUENCY VENTILATION VERSUS CONVENTIONAL VENTILATION IN SURFACTANT DEFICIENT RABBITS: EFFECTS ON GASEXCHANGE AND PRESSURE VOLUME CHARACTERISTIC OF THE LUNG.

Bambang Detomo S., Reyngoud D-J., Mook P., Wildevuur Ch.R.H. and Okken A. Div Neonatology, Depts Paediatrics and Thoracic Surgery, State University Groningen, The Netherlands.

Fo compare the effects of High Frequency Jet Ventilation (HFJV) and Conventional Ventilation (CV) in Respiratory Distress Syndrome, we induced surfactant deficiency in adult rabbits by lung lavage. 6 Animals were subjected to HFJV and 6 to $\mathrm{CV}$ (controls). HFJV and CV were set in such a way that normocarbia was obtained in the first $30 \mathrm{~min}$ of the study period. Thereafter ventilator settings were not changed. Results: $\mathrm{Pa} 02$ increased within $30 \mathrm{~min}$ from $8.36 \pm 0.80$ (mean \pm SEM) to $33.14 \pm 4.14 \mathrm{kPa}$ $(p<0.01)$ in the HFJV ventilated animals. No significant increase was found in the $\mathrm{CV}$ ventilated animals. $\mathrm{PaCO} 2$ in the $\mathrm{CV}$ group in creased gradually and maintained higher than in the HFJV group. In vitro static lung compliances were $0.95 \pm 0.09$ and $0.33 \pm 0.09$ $\mathrm{m} 1 / \mathrm{cm} \mathrm{H} 20 / \mathrm{Kg}$ body weight in the HFJV group and in the $\mathrm{CV}$ group respectively $(p<0.05)$. Conclusion: In surfactant deficient rabbits HFJV results in a better gasexchange than $C V$. A higher static lung compliance after HFJV might indicate that the lung is less atelectic than after $C V$.

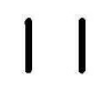

\section{ANTENATAL AMINOPHYLLINE ADMINISTRATION}

Firmino F.Rubaltelli, Pasquale Grella, Laura Di Lenar do, Bruno Granati. Departments of Pediatrics and Obstetrics, University of Padova School of Medicine.

Antenatal administration of glucocorticoids (GC)

seems to decrease the incidence of RDS by means of various mechanisms including surfactant production. Aminophylline (AF) has also been proposed for the prevention of RDS. We have evaluated the effect of antenatal AF treatment $(2,5 \mathrm{mg} / \mathrm{kg} / \mathrm{hr}$ for 3 days) on the frequency of RDS in 30 preterm newborns $\leq 32$ weeks of gestational age and compared this treatment with the GC administration (betametasone $4 \mathrm{mg}$ i.m. every $8 \mathrm{hrs}$ for $48 \mathrm{hrs}$ ) given to 18 mothers delivering premature newborns ( $\leq 32$ weeks g.a.). Thirty-two premature newborns $(\leq 32$ weeks g.a.) born to mothers not receiving drugs served as controls. In this series, $\mathrm{AF}$ was able to significantly reduce the incidence of RDS type II (Fisher test $=0.03$ ), but not the incidence of RDS type I (Fisher test $=$ $0.07)$. The mortality rate was 4 out of 30 . On the contrary GC did not significantly reduce either RDS type I or type II (Fisher test $=0.5$ and 0.25 ). In this group 5 out of 18 premature newborns did not survive. In the control group the survival rate was 23 out of 32. AF did appear to be well tolerated by the mother and seems to act on the fetus stimulating the respiratory center and possibly decreasing the fluid filtration across the alveolar-capillary barrier, reducing RDS type II.

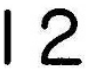

PHARMACOKINETICS ARD PULMONARY FUNCTICN FCLLOWING A

TEST DOSE OF I.V. SALBUTAMCL IN VENTILATED INFANTS WITH ERONCHOPULMONARY DYSPLASIA (EPD).

H Kirpalani, E Schmidt, G Koren, R Santos, S England, AC Eryan, Div. of Neonatal., Pharmacol. and Resp.

Physiol., kosp. for Sick Children, Toronto, Canada. Pharmacokinetics and pharmacodynamics of i.v. salbutamol $(1.0 \mathrm{\mu g} / \mathrm{kg} / \mathrm{m}$ in for $30 \mathrm{~min}$ ) were studied in 6 ventilator-dependent infants with BPD (GA 24-23 weeks, postnatal age 50-90 days). Passive respiratory system compliance (Crs), resistance (R), heart rate (UR), blood pressure (RP) and arterial blood gas tensions $(A B G)$ were recorded before and up to 6 hours post-infusion. E1imination T1/2 of salbutamol was $133 \pm 27$ min ( $\bar{x} \pm$ SLM), distribution volume (Vd) $1277 \pm 486 \mathrm{ml} / \mathrm{kg}$ and clearance $7.72 \pm 3.33 \mathrm{mI} / \mathrm{kg} /$ min. Tl/2 appears to be shorter than in healthy adults, probably due to smaller vd associated with tissue hypoperfusion. Crs improved immediately in 5 patients. Increments ranged from 0.45$2.04 \mathrm{ml} / \mathrm{cm} .20 / \mathrm{m}$ body length (23-145\% of pre-drug val.?ues). The subsequent fall of $\mathrm{Crs}$ paralleled the fall of druy levels. The 6th infant had a delayed rise in Crs at $6 \mathrm{hrs}$ post-infusion. This may be explained by a particularly small volume of distribution $(200 \mathrm{ml} / \mathrm{kg})$, suggesting delayed delivery of the drug to tissue receptors. $R$ fell in 4 infants $(22-35 \%$ of pre-trus levels). HR rose from $\bar{x}=153 / \mathrm{m}$ in to $\bar{x}=206 / \mathrm{min}$, concurrent with peak drug leve1s. No consistent changes were seen for BP and $A B G$. We conclude that following this test dose of $i . v$. salbutámol in infants with BPD, (1) $\mathrm{T} 1 / 2=133 \pm 27 \mathrm{~min}$; (2) Crs improves immediately in most patients; (3) increased Crs is not always accompanied by tecreased $\mathrm{R}$; (4) increased $\mathrm{Crs}$ is not associated with improved $A B G$; (5) tachycardia is a serious side-effect. 